\title{
Aging, female sex, migration, elevated HDL-C, and inflammation are associated with prevalence of metabolic syndrome among African bank employees
}

\author{
This article was published in the following Dove Press journal: \\ International Journal of General Medicine \\ 7 June 2012 \\ Number of times this article has been viewed
}

\author{
Thierry Gombet ${ }^{1}$ \\ Benjamin Longo-Mbenza ${ }^{2}$ \\ Bertrand Ellenga-Mbolla' \\ Meo Stephane Ikama ${ }^{3}$ \\ Etienne Mokondjimobe ${ }^{4}$ \\ Gisele Kimbally-Kaky ${ }^{3}$ \\ Jean-Louis $\mathrm{Nkoua}^{3}$ \\ 'Emergency Department, University \\ Hospital Center of Brazzaville, \\ Brazzaville, Congo; 'Faculty of Health \\ Sciences, Walter Sisulu University, \\ Mthatha, Eastern Cape, South Africa; \\ ${ }^{3}$ Department of Cardiology and \\ Internal Medicine, University Hospital \\ Center of Brazzaville, Brazzaville, \\ Congo; ${ }^{4}$ Laboratory of Biochemistry \\ and Pharmacology, Faculty of Health \\ Sciences, Brazzaville, Congo
}

Correspondence: Benjamin Longo-Mbenza Walter Sisulu University, Faculty of Health Sciences, Private Bag XI, Mthatha 5II7, Eastern Cape, South Africa

Tel +27 732822843

Email longombenza@gmail.com
Background: The objective of this study was to compare four different criteria for diagnosing metabolic syndrome (MS) and to correlate sociodemographic data, liver enzymes, lipids, inflammation, and insulin resistance with MS definitions.

Methods: This cross-sectional study included a random number of 126 African bank employees from Brazzaville, Congo.

Results: The prevalence of MS varied according to the different definitions used: $4.8 \%$ under World Health Organization (WHO) criteria, 8.7\% under the National Cholesterol Education Program Adult Treatment Panel III (NECP-ATPIII) criteria, 14.3\% under the International Diabetes Federation (IDF) for Europe, and $15.9 \%$ by the IDF for Central Africa. According to the IDF, specific cutoff points for the erythrocyte sedimentation rate, $\geq 13 \mathrm{~mm}$ at first hour and $\geq 30 \mathrm{~mm}$ at second hour, defined MS for Central Africa. The best agreement was observed between the IDF for Europe and the IDF for Central Africa (Kappa $=0.938 ; P<0.0001)$ criteria. The worst agreements were between the WHO and IDF for Central Africa (Kappa $=0.419$; $P<0.0001)$ criteria and between the WHO and IDF for Europe (Kappa $=0.462 ; P<0.0001)$ criteria. The NECP-ATPIII criteria did not agree with either the IDF for Europe or the IDF for Central Africa criteria. There was a significant relationship between female sex, aging, elevated liver enzymes, elevated phospholipids, high homeostasis model assessment of insulin resistance, and MS defined by the IDF for Central Africa.

Conclusion: The IDF definition of the MS modified for Central Africa provides higher prevalence estimates of MS than the estimates based on the NECP-ATPIII and IDF for Europe criteria. Liver enzymes, phospholipids, and homeostasis model assessment of insulin resistance should be included in clinical practice to stratify cardiovascular disease risk among Africans.

Keywords: metabolic syndrome, insulin resistance, inflammation, liver enzymes, atherosclerosis, sub-Saharan Africa

\section{Introduction}

Metabolic syndrome (MS) is a cluster of metabolic, inflammatory, and hemodynamic abnormalities. These interrelated abnormalities are associated with the onset of the atherosclerotic cardiovascular diseases (CVD) ${ }^{1}$ and type 2 diabetes mellitus (T2DM). ${ }^{2}$ Various combinations of abdominal obesity, elevated blood pressure (BP), elevated glycaemia, dyslipidemia, and insulin resistance have been proposed as criteria to diagnose MS in clinical practice. ${ }^{3-6}$ 
The prevalence of MS varies greatly by country, ethnicity, level of economic development, and residence because of the various definitions used in general populations: $6 \%$ in Japan, ${ }^{7} 11 \%$ in Finland, ${ }^{1} 27 \%$ in Mexico, ${ }^{8} 32 \%$ in India, ${ }^{9}$ $34 \%$ in African-Americans, and 39\% in white Americans. ${ }^{10}$ In sub-Saharan Africa, the most deleterious impact of demographic transitions and lifestyle changes ${ }^{11,12}$ on MS prevalence comes from the southern regions of subSaharan Africa: $43 \%$ in black diabetic Zimbabweans, ${ }^{13} 60 \%$ among South African blacks with established coronary artery disease, ${ }^{14}$ and $31 \%$ among South African corporate executives. ${ }^{15}$ However, in Central Africa, the use of international criteria underestimates the prevalence of MS in Cameroon: ${ }^{16} 1.8 \%-7.3 \%$ under the World Health Organization (WHO) criteria, $0 \%-1 \%$ under the National Cholesterol Education Program Adult Treatment Panel III (NCEPATPIII) criteria, and $0 \%-1.5 \%$ under the International Diabetes Federation (IDF) criteria. Further, it is difficult to define MS among Central and Western Africans, as the lipid profile is low or is less atherogenic and high-density lipoprotein cholesterol (HDL-C) is not useful because its high concentration is positively related to total cholesterol (TC) and cardiometabolic disease. ${ }^{16-18}$ In response to those controversies and the use of European cutoff points for waist circumference (WC), which are recommended in African populations because there is a of lack of specific and ethnic cutoff points for abdominal obesity, ${ }^{6}$ recently, we found that $\mathrm{WC} \geq 94 \mathrm{~cm}$ in both Central African men and women was the optimal cutoff for identifying individuals at high risk of developing CVD, dysglycemia, and arterial hypertension. ${ }^{17}$

In view of this, we wished to ascertain whether MS prevalence increased among these bank employees after rural-urban migration and sedentary lifestyle in Brazzaville city, Congo, considering sedentary workers at high risk after rural-urban migration. Indeed, the workplace is an important setting for primary and secondary preventions in industrialized countries, as MS leads to serious health problems such as T2DM, cardio-cerebrovascular risk, and comorbities as well as economic issues such as loss of productivity and healthcare, pharmacy, and short-term disability costs. ${ }^{19-24}$

The first aim of this study was to compare four different criteria for diagnosing MS: WHO ${ }^{4}{ }^{\mathrm{NCEP}}$-ATPIII, ${ }^{5} \mathrm{IDF}$ for Europe,${ }^{6}$ and IDF for Central Africa. ${ }^{17}$ The second objective of the study was to evaluate the correlation among sociodemographic characteristics, liver enzymes, lipids, inflammation, insulin resistance, and MS defined by the criteria indicating the highest rate.

\section{Methods}

\section{Study design}

This survey was a working community-based crosssectional study, conducted from December 1, 2008 to December 30, 2008 during the annual health examination mandated by law.

\section{Participants}

After excluding employees with fever, cough, infections, or tumors and pregnant women, the study was carried out among 126 bank employees drawn at random from the 1466 bank employees who had worked for more than 1 year in different private and public banks in Brazzaville City, Congo. The nature of their jobs varied and included maintenance, security, driving, clerical, managerial, and administrative tasks, which mainly involved handwriting, dictating, typing, ledger keeping, providing cash payment receipts, and mental activities. These are usually considered sedentary duties..$^{25}$

Informed consent from the participants and the bank authorities was obtained. The confidentiality and anonymity of every participant was maintained and all data were kept private. Ethical approval was obtained from the local ethics committee in the faculty of Health Sciences of Marien Ngouabi University, Brazzaville, Congo.

\section{Data collection}

Participants were invited to the banks medical center where the resident briefly explained the study concept and information was collected by trained interviewers, using a structured questionnaire. Effort was made in this study to maximize the response rate to minimize the potential biases. Data on demographic characteristics, socioeconomic status, work attendance, and duration of rural-urban migration, residence, personal and family medical history, and lifestyle/behavioral habits were self-reported.

Anthropometric and BP data were obtained during a comprehensive and standardized physical examination performed after an 8-12-hour fasting period, with the participant in light clothing and barefoot. Body height was measured to the nearest centimeter, with the participant standing, using a wall stadiometer. Body weight was measured to the nearest $0.1 \mathrm{~kg}$ using a calibrated balance beam scale (Soehnle-Waagen GmGh Co, Murrhardt, Germany). Body mass index (BMI) was calculated as weight in kilograms divided by height in meters, squared $\left(\mathrm{kg} / \mathrm{m}^{2}\right)$. WC was measured to the nearest $0.5 \mathrm{~cm}$ using a standard flexible and nondistensible tape and exertion of pressure on the tissues was avoided, with the participant standing upright, after gentle expiration, at a point 
measured midway between the lower costal margin and the upper border of the iliac crest.

$\mathrm{BP}$ was measured using a standard mercury sphygmomanometer with the cuff long enough to encircle at least twothirds of the upper arm. Three BP readings were taken after the seated participant had rested for 10-15 minutes and the mean of the last two readings was calculated. If the difference between the two measures was $>5 \mathrm{mmHg}$ for systolic (SBP at Korotkoff I sound) and diastolic (DBP at Korotkoff IV sound) BP, a third measurement was taken and the mean of the two closest values was recorded for analysis.

A venous blood sample was drawn after an 8-12-hour overnight fast. Serum TC, low-density lipoprotein cholesterol (LDL-C), HDL-C, and triglycerides were assessed using automatic standard routine enzymatic methods and commercially available kits (Biomérieux, Marcy l'Etoile, France). The Wintrobe method was used to measure the erythrocyte sedimentation rate (ESR) in fresh blood samples obtained at the time of venesection.

Other important markers for MS, atherosclerosis, and liver diseases - such as phospholipids, homeostasis model assessment (HOMA), insulin resistance (IR) index, gammaglytamyl transferase (GGT), alanine aminotransferase (ALT), and aspartate aminotransferase (AST) - were measured at Lomo Medical Laboratories, Kinshasa, Congo, using different commercial reagents.

\section{Definitions}

Lifestyle/Behavioral habits included cigarette smoking (those who had never smoked vs those who had smoked during the previous 12 months), physical activity (inactive with a median continuous index derived from hours of walking for relaxation or exercise, on the way to and from work $<60$ minutes vs physically active $\geq 60$ minutes $),{ }^{26}$ and excessive alcohol intake (yes vs no). Excessive alcohol intake was defined as a combination of more than four drinks per week, one drink per day, and two or more drinks per day, whereas no excessive alcohol intake was defined as rarely drinking, never drinking, one to three drinks per month, and less than three drinks per week. ${ }^{27}$

Four operational definitions of MS were used. The first of these was the WHO definition as modified by the European Group for the Study of Insulin Resistance for application in epidemiological studies. ${ }^{28}$ According to the IDF definition with European cutoffs, the second definition used, a male with a $\mathrm{WC} \geq 94 \mathrm{~cm}$ or a female with a WC $\geq 80 \mathrm{~cm}$ has MS if they also have two or more of the following: triglycerides $\geq 150 \mathrm{mg} / \mathrm{dL}(1.7 \mathrm{mmol} / \mathrm{L})$ or specific treatment for this lipid abnormality, reduced concentration of HDL-C $<40 \mathrm{mg} / \mathrm{dL}(1.03 \mathrm{mmol} / \mathrm{L})$ in men and $<50 \mathrm{mg} / \mathrm{dL}(1.29 \mathrm{mmol} / \mathrm{L})$ in women or specific treatment for this lipid abnormality, SBP $\geq 130 \mathrm{mmHg}$ or DBP $\geq 85 \mathrm{mmHg}$ or treatment of previously diagnosed hypertension, and fasting plasma glucose $\geq 100 \mathrm{mg} / \mathrm{dL}$ $(5.6 \mathrm{mmol} / \mathrm{L})$ or previously diagnosed T2DM. Modified IDF definition for Central Africans, ${ }^{17}$ the third definition used, used the ethnic group-specific threshold of $\mathrm{WC} \geq 94 \mathrm{~cm}$ in both men and women plus the IDF's other criteria. ${ }^{6}$ The final definition used was the NCEP-ATPIII. According to the NCEP-ATPIII report, ${ }^{5}$ participants who had three or more of the following were defined as having MS: abdominal obesity ( $\mathrm{WC} \geq 102 \mathrm{~cm}$ in men and $\geq 88 \mathrm{~cm}$ in women), triglycerides $\geq 150 \mathrm{mg} / \mathrm{dL}(1.7 \mathrm{mmol} / \mathrm{L}), \mathrm{HDL}-\mathrm{C}<40 \mathrm{mg} / \mathrm{dL}$ $(1.03 \mathrm{mmol} / \mathrm{L})$ in men and $<50 \mathrm{mg} / \mathrm{dL}(1.29 \mathrm{mmol} / \mathrm{L})$ in women, $\mathrm{SBP} \geq 130 \mathrm{mmHg}$ or $\mathrm{DBP} \geq 85 \mathrm{mmHg}$, and fasting plasma glucose $\geq 100 \mathrm{mg} / \mathrm{dL}(5.6 \mathrm{mmol} / \mathrm{L})$.

Cardiometabolic conditions included subclinical atherosclerosis and T2DM. Subclinical atherosclerosis was defined as pulse pressure $\geq 60 \mathrm{mmHg}$. ${ }^{26}$

\section{Statistical analysis}

Data were described as mean values \pm standard deviations for continuous variables. Counts and proportions (\%) were reported for categorical variables. Proportions were compared using the chi-square test or Fischer's exact test, whenever appropriate. Student's $t$-test was used to compare means between groups. Univariate odds ratio (OR) using Maentel-Haenszel and multivariate OR using logistic regression analysis were calculated with their 95\% confidence intervals (CIs) to define any association between MS defined by IDF modified for Central Africa and risk factors, as well between MS defined by IDF for Europe and risk factors. The effective cutoff values of traditional and new components of MS were tested using receiver operating characteristic (ROC) curves.

The Kappa coefficient was used to analyze statistical agreement among the WHO, NCEP-ATPIII, IDF with European cutoffs, and IDF modified for Central Africans definitions of MS. The criterion for statistical significance was $P$ value $<0.05$. All analyses were conducted using SPSS software (v 13.0; SPSS Inc, Chicago, IL).

\section{Results}

The study population $(\mathrm{n}=126)$ was at high cardiovascular risk (Table 1), with epidemic rates of the traditional components of MS (hypertension, hyperglycemia, and obesity), 
Table I Cardiovascular risk factors among the bank employees

\begin{tabular}{|c|c|c|c|c|c|}
\hline Variables & n/total & $\%$ & Men (\%) & Women (\%) & $P$-value \\
\hline \multicolumn{6}{|l|}{ Sex } \\
\hline Men & $70 / 126$ & 55.6 & & & \\
\hline Women & $56 / 126$ & 44.4 & & & \\
\hline Smoking & $5 / 124$ & 3.2 & 5.7 & 0 & $<0.05$ \\
\hline Excessive alcohol intake & $42 / 125$ & 33.6 & 44.3 & 21.4 & 0.007 \\
\hline Physical inactivity & $108 / 126$ & 85.7 & 75.7 & 98.2 & $<0.0001$ \\
\hline Known hypertension & $33 / 126$ & 26.2 & 17.1 & 37.5 & $<0.01$ \\
\hline Pulse pressure $\geq 60 \mathrm{mmHg}$ & $38 / 126$ & 30.2 & 31.4 & 29 & 0.842 \\
\hline Stress & $24 / 126$ & 19 & 9 & 29 & $<0.0001$ \\
\hline Overweight/total obesity & $82 / 126$ & 65.1 & 55 & 75 & $<0.0001$ \\
\hline \multicolumn{6}{|l|}{ Abdominal obesity } \\
\hline NCEP-ATPIII & $50 / 126$ & 39.7 & 21.4 & 62.5 & $<0.0001$ \\
\hline IDF & $80 / 126$ & 63.5 & 50 & 77 & $<0.0001$ \\
\hline IDF Central Africa & & 43.7 & 42.9 & 44.6 & 0.841 \\
\hline Fasting glycemia $\geq 100 \mathrm{mg} / \mathrm{dL}$ & $33 / 126$ & 26.2 & I7.1 & & $<0.01$ \\
\hline
\end{tabular}

Abbreviations: NCEP-ATPIII, National Cholesterol Education Program Adult Treatment Panel III; IDF, International Diabetes Federation.

subclinical atherosclerosis, and excessive alcohol intake. The sex ratio was 1.3 men to 1 woman. However, dyslipidemia, another component of MS, was heterogeneously constituted: very low rates of hypertriglyceridemia $(3.9 \%, \mathrm{n}=5)$, T2DM $(7.9 \%, \mathrm{n}=10)$, and low HDL-C $(9.5 \%, \mathrm{n}=12)$, moderate increase of elevated LDL-C $(23 \%$, $\mathrm{n}=29)$, and a high rate of hypercholesterolemia $(40.4 \%$, $\mathrm{n}=51$ ). Compared with men, women were more vulnerable for physical inactivity, hypertension, high pulse pressure, obesity, dysglycemia, and stress, but less vulnerable for smoking and excessive alcohol intake. However, abdominal obesity, as defined by the IDF for central Africa, was similar in men and women. GGT, ALT, and AST values were within the normal references.

Men and women had similar mean values of age, duration of rural-urban migration, WC, SBP, and DBP were similar $(P>0.05)$, whereas, compared with men, women had significantly higher BMI, TC, LDL-C, HOMA-IR, AST, phospholipids, ESR rate at first hour (ESR 1st H), and ESR at second hour (ESR 2nd H), but significantly lower mean values of triglycerides, HDL-C, GGT, and ALT (Table 2).

The prevalence of MS varied from $4.8 \%(n=6)$ using the WHO criteria to $15.9 \%(n=20)$ when the IDF modified for Central Africa was used, with intermediate values obtained

Table 2 Mean values of characteristics by gender

\begin{tabular}{|c|c|c|c|c|}
\hline Variables & All & Men & Women & $P$-value \\
\hline Age (years) & $42 \pm 9$ & $41 \pm 9$ & $43 \pm 9$ & 0.145 \\
\hline Rural-urban migration (years) & $7 \pm 10$ & $7 \pm 10$ & $6 \pm 9$ & 0.531 \\
\hline Body mass index $\left(\mathrm{kg} / \mathrm{m}^{2}\right)$ & $27.2 \pm 5.1$ & $26 \pm 4.4$ & $28.6 \pm 5.6$ & 0.004 \\
\hline Waist circumference $(\mathrm{cm})$ & $92.1 \pm 12.3$ & $91.8 \pm 12.3$ & $92.6 \pm 12.5$ & 0.724 \\
\hline Systolic blood pressure (mmHg) & $14 \mid .4 \pm 23.2$ & $|4| .2 \pm 24.3$ & $|4| .7 \pm 22 . \mid$ & 0.898 \\
\hline Diastolic blood pressure $(\mathrm{mmHg})$ & $87.1 \pm 13.6$ & $86.4 \pm 14.8$ & $88 \pm 12$ & 0.503 \\
\hline Total cholesterol (mg/dL) & $200.1 \pm 48$ & $190.6 \pm 43.8$ & $213.5 \pm 50.9$ & 0.014 \\
\hline HDL-C (mg/dL) & $80.5 \pm 31.6$ & $91.9 \pm 33.2$ & $69.1 \pm 29.4$ & $<0.0001$ \\
\hline Triglycerides (mg/dL) & $75.9 \pm 39.4$ & $83.8 \pm 43.6$ & $64.9 \pm 29.6$ & 0.013 \\
\hline LDL-C (mg/dL) & $105 \pm 61.5$ & $93.7 \pm 57$ & $|2| . \mid \pm 64.8$ & 0.023 \\
\hline ESR Ist $\mathrm{H}(\mathrm{mm} / \mathrm{H})$ & $14.8 \pm 12.2$ & $8.8 \pm 7.8$ & $23 \pm 12.3$ & $<0.0001$ \\
\hline ESR 2nd H $(\mathrm{mm} / \mathrm{H})$ & $32 \pm 21$ & $21 \pm 15$ & $47 \pm 18$ & $<0.0001$ \\
\hline HOMA-IR & $1.3 \pm 0.9$ & $1.1 \pm 1$ & $1.4 \pm 1.2$ & $<0.001$ \\
\hline Gamma-glutamyl transferase (IU/L) & $29 \pm 12$ & $38 \pm 10$ & $20 \pm 9$ & $<0.001$ \\
\hline Alanine amino-transferase (IU/L) & $18 \pm 6$ & $21 \pm 12$ & $15 \pm 8$ & $<0.001$ \\
\hline Aspartate amino-transferase (IU/L) & $23 \pm 12$ & $21.6 \pm 10$ & $24.2 \pm 13.8$ & 0.007 \\
\hline Phospholipids (mg/dL) & $233.2 \pm 37$ & $205 \pm 37$ & $260.5 \pm 39$ & $<0.001$ \\
\hline
\end{tabular}

Abbreviations: HDL-C, high density lipoprotein-cholesterol; LDL-C, low density lipoprotein-cholesterol; ESR Ist H, erythrocyte sedimentation rate at first hour; ESR 2nd H, erythrocyte sedimentation rate at second hour; HOMA-IR, homeostasis model assessment-insulin resistance. 
when the NCEP-ATPIII was used $(8.7 \%, \mathrm{n}=11)$ and the IDF with Europid criteria was used $(14.3 \%, \mathrm{n}=18)$.

There was no significant association between cigarette smoking, excessive alcohol intake, physical inactivity, and the presence of MS using the different definitions (results not shown). MS defined by NCEP-ATPIII and IDF for Europe were more prevalent $(P=0.009$ and $P=0.040)$ among female participants $(16.1 \% \mathrm{n}=9 / 56$; OR $=595 \%$ CI $1.2-25)$ in NCEP-ATPIII definition and $21.4 \% \mathrm{n}=12 / 56$; OR $=3.395 \%$ CI 1.1-8 in IDF for Europe definition than in male participants $(2.9 \% \mathrm{n}=2 / 70$; in NCEP-ATPIII definition $\mathrm{OR}=0.2$ 95\% CI 0.03-0.74). However, there was no significant impact of sex on the prevalence of MS defined by WHO and IDF for Central Africa.

When NCEP-ATPIII criteria were used, participants with MS had significantly higher means of age, TC, LDL-C, ESR 1st H, ESR 2nd H, and rural-urban migration duration than their counterparts without MS (Table 3). Increase in mean values of age, TC, LDL-C, ESR 1st H, HOMA-IR, GGT, ALT, AST, phospholipids, and ESR 2nd H was significantly associated with the prevalence of MS as defined by the IDF modified for Central Africa (Table 4).

Elevated LDL-C ( $\geq 130 \mathrm{mg} / \mathrm{dL})$ was more prevalent among participants with MS defined by the WHO criteria than among those defined by the NCEP-ATPIII criteria and IDF Europid criteria (Figure 1). However, LDL-C $\geq 130 \mathrm{mg} / \mathrm{dL}$ was similarly $(P=0.217)$ frequent in MS defined by IDF Europid criteria $(24.1 \% \mathrm{n}=7 / 18)$ and in absence of MS $(24.7 \% \mathrm{n}=22 / 89)$.

Overweight/Total obesity conferred five times greater risk of MS when defined by the IDF Europid criteria $(\mathrm{OR}=5.1,95 \%$ CI $1.1-23.3$, rate of $20 \%, \mathrm{n}=16 / 80$; $P=0.022)$ in comparison with optimal weight $(\mathrm{OR}=1$, rate of $4.3 \%, n=2 / 46$ ).

Table 3 Variables significantly associated with metabolic syndrome

\begin{tabular}{lccl}
\hline Variables & $\begin{array}{l}\text { Presence of } \\
\text { MS/NCEP- } \\
\text { ATPIII }\end{array}$ & $\begin{array}{l}\text { Absence of } \\
\text { MS/NCEP- }\end{array}$ & P-value \\
& ATPIII & \\
\hline Age (years) & $47.7 \pm 6.6$ & $4 I .4 \pm 8.7$ & $0.02 \mathrm{I}$ \\
Total cholesterol (mg/dL) & $253 \pm 62.5$ & $194.1 \pm 42.5$ & $<0.000$ I \\
LDL-C $(\mathrm{mg} / \mathrm{dL})$ & $149.8 \pm 71.2$ & $99.9 \pm 58.6$ & $<0.0 \mathrm{I}$ \\
ESR Ist H (mm/H) & $21.6 \pm 15.8$ & $14 \pm 11.5$ & 0.047 \\
ESR 2nd H (mm/H) & $45 \pm 20$ & $30.4 \pm 20.5$ & 0.048 \\
Rural-urban migration & $15.3 \pm 14.5$ & $5.8 \pm 8.8$ & 0.004 \\
duration in years & & & \\
\hline
\end{tabular}

Abbreviations: MS, metabolic syndrome; NCEP-ATPIII, National Cholesterol Education Program Adult Treatment Panel III; LDL-C, low density lipoproteincholesterol; ESR Ist $\mathrm{H}$, erythrocyte sedimentation rate at first hour; ESR 2nd $\mathrm{H}$, erythrocyte sedimentation rate at second hour.
Only MS defined by the IDF for Central Africa $(\mathrm{OR}=3.8$, 95\% CI 1.6-42.7; $P=0.004)$ and the WHO criteria $(\mathrm{OR}=5$, $95 \%$ CI $1.3-55 ; P=0.046)$ increased significantly the risk of subclinical atherosclerosis.

MS defined by the WHO criteria was not associated $(P>0.05)$ with the prevalence of T2DM $(\mathrm{OR}=0.9,95 \% \mathrm{CI}$ $0.7-1.3 ; P=0.841,7.8 \%, \mathrm{n}=10)$. However, the definitions of MS based on prerequisite WC cutoff points conferred a significant risk of T2DM: the highest proportion of T2DM being observed in MS defined by the IDF modified for Central Africa $(45 \%, \mathrm{n}=9 / 20, \mathrm{OR}=85.1,95 \%$ CI 9.9-74.2; $P<0.0001)$, the intermediate risk for T2DM in MS defined by IDF for Europe $(44.4 \%, \mathrm{n}=8 / 18, \mathrm{OR}=42.4,95 \% \mathrm{CI}$ 7.9-127.4; $P<0.0001)$ and the lower risk for T2DM in MS defined by NCEP-ATPIII $(\mathrm{n}=5 / 10, \mathrm{OR}=18.3,95 \% \mathrm{CI}$ 4.1-81; $P<0.0001)$.

Paradoxically, there was a significant inverted U-shaped relationship between MS and HDL-C categories: MS being more $(P<0.005)$ prevalent among participants with normal and high HDL-C levels than in participants with low HDL-C. MS defined by the IDF modified for Central Africa detected higher rates of the clustering of cardiovascular risk factors at each HDL-C strate than MS defined by the WHO, NCEP-ATPIII, and IDF Europe criteria.

Classifications of MS measured by Kappa statistics varied widely: the best agreement was obtained between MS/IDF for Central Africa and MS/IDF for Europe (Kappa = 0.938; $P<0.0001)$; intermediate and good between MS/IDF Europe and NCEP-ATPIII (Kappa $=0.729 ; P<0.0001)$ as well as for MS/IDF for Central Africa and NCEP-ATPIII (Kappa $=0.673 ; P<0.0001)$. The worst agreement was between the IDF for Central Africa and WHO definitions (Kappa $=0.419 ; P<0.0001$ ) as well between the IDF for Europe and WHO definitions (Kappa $=0.462$; $P<0.0001)$.

Figure 2 shows the ROC curves of ESR 1st H and ESR 2nd $\mathrm{H}$ detecting the clustering of cardiovascular risk factors according to the NCEP-ATPIII and IDF Europid criteria. The area under the ROC curve was 0.71 (95\% CI 0.60-0.83; $P=0.021)$ for ESR 1 st $\mathrm{H}$ and 0.71 (95\% CI $0.60-0.83$; $P=0.023)$ to detect MS/NCEP-ATPIII. The area under the ROC curve was 0.70 (95\% CI $0.57-0.81 ; P=0.014)$ for ESR 1 st $\mathrm{H}$ and $0.70(95 \%$ CI $0.57-0.81 ; P=0.012)$ for ESR 2nd $\mathrm{H}$ to detect MS/IDF Europid criteria. From the curves, ESR 1 st $\mathrm{H} \geq 13 \mathrm{~mm} / \mathrm{H}$ (sensitivity $=91 \%$ and specificity $=60 \%$ ) and $\mathrm{ESR} 2 \mathrm{nd} \mathrm{H} \geq 30 \mathrm{~mm} / \mathrm{H}$ (sensitivity $=91 \%$ and specificity $=60 \%$ ) seemed to be effective values for 
Table 4 Mean values of ages, TC, LDL-C, and ESR by presence of metabolic syndrome by IDF modified for Central Africa

\begin{tabular}{|c|c|c|c|c|}
\hline Variables & Total & $\begin{array}{l}\text { Presence of MS/IDF } \\
\text { for Central Africa }\end{array}$ & $\begin{array}{l}\text { Absence of MS/IDF } \\
\text { for Central Africa }\end{array}$ & $P$-value \\
\hline Age (years) & $42 \pm 8.76$ & $46.6 \pm 7.3$ & $4 \mathrm{I} .2 \pm 8.7$ & 0.015 \\
\hline $\mathrm{TC}(\mathrm{mg} / \mathrm{dL})$ & $200 \pm 48$ & $230.7 \pm 66.6$ & $194 \pm 41.2$ & 0.003 \\
\hline LDL-C (mg/dL) & $105 \pm 61.5$ & $132.3 \pm 69.9$ & $99.5 \pm 58.6$ & 0.039 \\
\hline ESR Ist $\mathrm{H}(\mathrm{mm} / \mathrm{H})$ & $14.8 \pm 12.2$ & $20.6 \pm 14.7$ & $13.6 \pm 11.3$ & 0.030 \\
\hline ESR 2nd $\mathrm{H}(\mathrm{mm} / \mathrm{H})$ & $31.7 \pm 20.7$ & $42.1 \pm 20.9$ & $29.7 \pm 20.1$ & 0.023 \\
\hline HOMA-IR & $1.3 \pm 0.9$ & $1.8 \pm 1.1$ & $0.8 \pm 0.6$ & $<0.0001$ \\
\hline Gamma-glutamyl transferase (IU/L) & $29 \pm 12$ & $35.4 \pm 10$ & $22.6 \pm 11$ & $<0.001$ \\
\hline Alanine amino-transferase (IU/L) & $18 \pm 6$ & $24 \pm 7$ & $12 \pm 5.9$ & $<0.0001$ \\
\hline Aspartate amino-transferase (IU/L) & $23 \pm 12$ & $37.5 \pm 11.1$ & $8.5 \pm 6$ & $<0.000$ I \\
\hline Phospholipids (mg/dL) & $233.2 \pm 37$ & $296.6 \pm 38$ & $169.8 \pm 39$ & $<0.000$ I \\
\hline
\end{tabular}

Abbreviations: TC, total cholesterol; LDL-C, low density lipoprotein-cholesterol; ESR, erythrocyte sedimentation; IDF, International Diabetes Federation; ESR Ist H, erythrocyte sedimentation rate at first hour; ESR 2 nd $\mathrm{H}$, erythrocyte sedimentation rate at second hour; HOMA-IR, homeostasis model assessment-insulin resistance.

MS/NCEP-ATPIII. For MS/IDF Europid criteria, ESR $1 \mathrm{st} \mathrm{H} \geq 13 \mathrm{~mm} / \mathrm{H}$ (sensitivity $=82 \%$ and specificity $=61 \%$ ) and $\mathrm{ESR} 2 \mathrm{nd} \mathrm{H} \geq 30 \mathrm{~mm} / \mathrm{H}$ (sensitivity $=82 \%$ and specificity $=61 \%$ ) and ERS $2 \mathrm{nd} \mathrm{H} \geq 30 \mathrm{~mm} / \mathrm{H}$ (sensitivity $=82 \%$ and specificity $=61 \%$ ) seemed also to be effective values for MS/IDF Europid criteria.

The areas under the ROC curves for HDL-C, TC, triglycerides, and LDL-C to detect MS defined by different criteria were not statistically significant for these African bank employees (curves not shown).

Adjusted for sex, total obesity, TC $\geq 200 \mathrm{mg} / \mathrm{dL}$, LDL-C $\geq 130 \mathrm{mg} / \mathrm{dL}$, physical inactivity, duration of ruralurban migration, energy expenditure, and high socioeconomic status in each logistic regression model, only being aged $\geq 45$ years was significantly and independently associated with MS as defined by the IDF for Europe (OR $=4.5$, $95 \%$ CI $1.5-14 ; P=0.009$, standard error $=0.519$, Wald

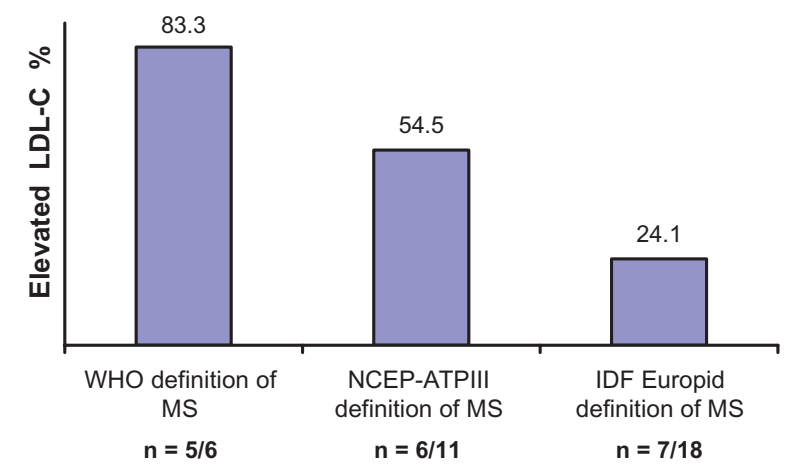

Figure I Prevalence of elevated low density lipoprotein-cholesterol ( $\geq 130 \mathrm{mg} / \mathrm{dL}$ ) according to metabolic syndrome (MS) defined by the World Health Organization (WHO), National Cholesterol Education Program Adult Treatment Panel III (NCEPATPIII), and International Diabetes Federation (IDF) Europid criteria.

Abbreviation: LDL-C, low density lipoprotein-cholesterol. chi-square $=6.749)$ and by the IDF modified for Central Africa $(\mathrm{OR}=4.5,95 \%$ CI $1.4-11 ; P<0.0001)$.

\section{Discussion}

\section{Prevalence of MS}

As reported in the literature, ${ }^{1,8-16,29}$ the prevalence of MS varied according to the definitions used. The prevalence of

A

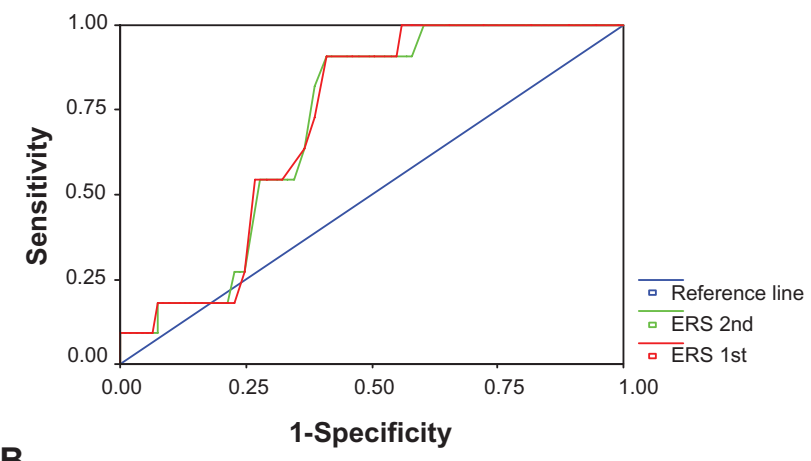

B

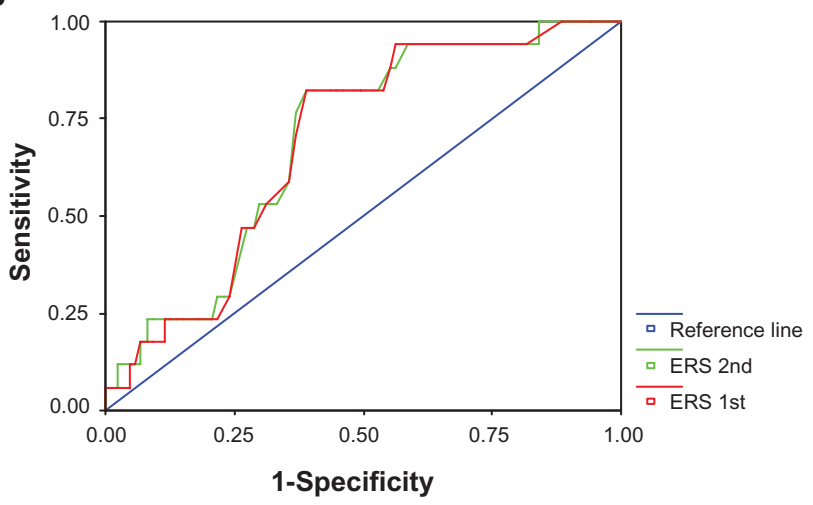

Figure 2 Receiver operating characteristics curves of erythrocyte sedimentation rate (ESR) at first (Ist) and second (2nd) hour to detect metabolic syndrome according to National Cholesterol Education Program Adult Treatment Panel III (A) and International Diabetes Federation Europid (B) definitions. 
MS was lowest with the WHO definition (4.8\%), followed by the NCEP-ATPIII definition (8.7\%) and the IDF definition for Europeans (14.3\%), and highest using the IDF definition modified for Central Africa (15.9\%). The combined estimated MS prevalence from all definitions was similar to that from IDF definition modified for Central Africa. Our findings indicate that the prevalence of MS among these Central African Bank employees notably exceeds that in general Central African populations ${ }^{16}$ when using the NCEP-ATPIII and IDF for Europe definitions but not when the WHO definition is used. Indeed, MS defined by both IDF criteria (Europe and Central Africa) in this working population is 15 times higher $(14.3 \%-15.9 \%)$ than that observed in the Central African general population using the NCEP-ATPIII $(0 \%-1 \%)$ and IDF for Europe $(0 \%-1.5 \%)$ criteria. ${ }^{16}$ However, the prevalence of MS in these employees is totally lower than the $\geq 30 \% \mathrm{MS}$ prevalence reported in African working, in-patient, and general populations from Southern Africa. ${ }^{13-15}$ Studies from emergent and developed countries have reported lower or higher rates of MS in the workplace and in general populations than the present study. Lower prevalence of MS was reported in general populations of Japan in general $(6 \%)^{20}$ and Finland $(11 \%)^{1}$ as well as in working populations of Japan working $(9.1 \%)^{20}$ and South Korea (11.7\%). ${ }^{23}$ Higher prevalence of MS was reported in general populations of Mexico (27\%), ${ }^{8}$ India (32\%), ${ }^{9}$ the USA $(30 \%-39 \%){ }^{10}$ and China $(18 \%-29 \%)^{38}$ as well as in working populations of Germany $(23.5 \%)^{24}$ and the USA $(30.2 \%){ }^{32}$ Such different prevalence rates across the world are difficult interpret. ${ }^{30,31}$

\section{Risk factors and determinants of MS}

In univariate analysis, female sex, proinflammatory state, aging, longer duration of rural-urban migration were individually and significantly associated with the presence of MS, therefore, they are considered risk factors for MS. However, in multivariate analysis, only advancing age ( $\geq 45$ years) was significantly and independently associated with the presence of MS among the bank employees studied. Therefore, advancing age was the only independent determinant of MS in this study. Advancing age is also considered a contributing factor to MS in the US population..$^{32}$ Demographic transition ${ }^{12}$ affects all levels of cardiometabolic pathogenesis among Africans. ${ }^{13-18}$ In European populations, ${ }^{29,33}$ the prevalence of MS is highly age dependent in both males and females, regardless of the criteria used.
The present study has shown that the influence of sex on MS prevalence is dependent on the definition used. The WHO and IDF modified for Central Africa criteria have shown similar estimates of MS in male and female bank employees, whereas, as expected, MS was more prevalent in women than men according to the NCEP-ATPIII and IDF for Europe definitions. Reports from the literature indicate higher prevalence of MS among men in the Lebanese general population ${ }^{34}$ and the German working population, ${ }^{24}$ whereas, MS is higher among women than men in Turkey, ${ }^{35}$ Oman, ${ }^{36}$ and Iran. ${ }^{37}$

The lack of a significant and independent association between overweight/total obesity and MS in this study suggests that MS/insulin resistance is also present in nonobese individuals as reported in Central Africans. ${ }^{17}$ Low prevalence of smoking and presence of physical inactivity in the majority of these employees may explain the absence of the association of these with MS - for example, as has been reported in China. ${ }^{38}$

In this study, a proinflammatory state, recognized as elevations of ESR (effective thresholds $\geq 13 \mathrm{~mm}$ at $1 \mathrm{st} \mathrm{H}$ and $\geq 30 \mathrm{~mm}$ at $2 \mathrm{nd} \mathrm{H}$ ), was an underlying and emerging risk factor of MS. Indeed, markers of inflammation, microalbuminuria, hyperuricemia, and fibrinolytic and coagulation abnormalities are being proposed as new components of MS. ${ }^{39,40}$ Multiple mechanisms, such as obesity, physical inactivity, and insulin resistance, determine elevations of ESR, C-reactive protein, fibrinogen, and cytokines.

\section{Rationale for a modification of the MS criteria for Central Africa}

As reported in our previous study, ${ }^{17}$ the present findings illustrate the limited role of international cutoff points of BMI, WC, 5,6 and HDL-C to arbitrarily define MS among sub-Saharan Africans. The criteria for the definition of MS were initially constructed from data in Caucasian populations. Altering the criteria of LDL-C and HDL-C for Central Africaspecific cutoffs, as has previously been done for BMI and WC in Congo Kinshasa ${ }^{17}$ and other Asian countries, ${ }^{41}$ will help in more accurate characterization of MS. Indeed, there is controversy about the utility of MS and that of its components in predicting cardiovascular risk.

The present study is consistent with several reports from the literature that demonstrate the association of MS with increased levels of GGT, ALT, and AST within normal ranges. ${ }^{42-44}$ Elevated liver enzymes in these bank employees may also reflect inflammation because of their sedentary 
lifestyle, oxidative stress, obesity, insulin resistance, hypertension, dysglycemia, and dyslipidemia associated with MS. In a recent South Korean study, serum ALT and GGT concentrations were within the reference ranges of MS in a linear manner. ${ }^{45}$

\section{Implications for public health}

As MS may be a cause of significant economic cost in terms of absenteeism, CVD-, and T2DM-related complications, employers would be wise to address the health risks of their employees through health promotion programs and benefit from plan designs that help individuals improve their health and to receive appropriate health screenings and medical care.

The trend of MS among these sedentary employees (15 times higher than that of the general population $)^{16}$ must be monitored in future studies.

GGT, ALT, and AST are becoming important additional biomarkers to the multimarker approach to MS and cardiovascular risk evaluation.

\section{Study limitations}

Despite the anticipation of errors, some limitations must be pointed out. The cross-sectional nature of this study meant that any causal relationship among WC, ESR, and cardiometabolic risk was not assessed.

Further, the sample size in this cross-sectional study was small and small samples are not usually strong enough to provide confident findings.

\section{Conclusion}

The results confirm the previous concept and have find that the use of the IDF definition of MS modified for Central Africa leads to higher prevalence estimate of MS than the estimates based on the NCEP-ATPIII and IDF for Europe criteria. Liver enzymes, phospholipids, and HOMA-IR should be included in practice to stratify CVD risk among Africans.

\section{Disclosure}

The authors report no conflicts of interest in this work.

\section{References}

1. Lakka HM, Laaksonen DE, Lakka TA, et al. The metabolic syndrome and total and cardiovascular mortality in middle-aged men. JAMA. 2002;288(21):2709-2716.

2. Ford ES. Risks for all-cause mortality, cardiovascular, and diabetes associated with the metabolic syndrome: a summary of the evidence. Diabetes Care. 2005;28(7):1769-1778.
3. Eckel RH, Grundy SM, Zimmet PZ. The metabolic syndrome. Lancet. 2005;365(9468):1415-1428.

4. Alberti KG, Zimmet PZ. Definition, diagnosis and classification of diabetes mellitus and its complications. Part 1: diagnosis and classification of diabetes mellitus provisional report of a WHO consultation. Diabet Med. 1998;15(7):539-553.

5. Expert Panel on Detection, Evaluation, and Treatment of High Blood Cholesterol in Adults. Executive Summary of the Third Report of The National Cholesterol Educational Program (NCEP) expert panel on detection, evaluation, and treatment of high blood cholesterol in adults (Adult Treatment Panel III). JAMA. 2001;285(19):2486-2497.

6. Alberti KG, Zimmet P, Shaw J; IDF Epidemiology Task Force Consensus Group. The metabolic syndrome - a new worldwide definition. Lancet. 2005;366(9491):1059-1062.

7. Enkhmaa B, Shiwaku K, Anuurad E, et al. Prevalence of the metabolic using the Third Report of the National Cholesterol Education Program Expert Panel on Detection, Evaluation and Treatment of High Blood Cholesterol in Adults (ATPIII) and the modified ATPIII definitions for Japanese and Mongolians. Clin Chim Acta. 2005;352(1-2):105-113.

8. Aguilar-Salinas CA, Rojas R, Gomez-Perez FJ, et al. High prevalence of the metabolic syndrome in Mexico. Arch Med Res. 2004;35(1): $76-81$.

9. Gupta R, Deedwania PC, Gupta A, Rastogi S, Panwar RB, Kothari K. Prevalence of metabolic syndrome in an Indian urban population. Cardiology. 2004;97(2):57-61.

10. Kraja AT, Hunt SC, Pankow JS, et al. An evaluation of the metabolic syndrome in the HyperGen study. Nutr Med (Lond). 2005;2(1): $17-25$.

11. World Health Organization. Non-Communicable Diseases: A Strategy for the African Region. Harare, Zimbabwe: WHO Regional Office for Africa; 2000.

12. Yusuf S, Reddy S, Ounpuu S, Anand S. Global burden of cardiovascular diseases: part I: general considerations, the epidemiologic transition, risk factors, and impact of urbanization. Circulation. 2001;104(22):2746-2753.

13. Makuyana D, Gomo Z, Munyombwe T, Matenga JA, Hakim JG. Metabolic syndrome disorders in urban black Zimbabweans with type 2 Diabetes mellitus. Cent Afr J Med. 2004;50(3-4):24-29.

14. Ntyintyane LM, Panz VR, Raal FJ, Gill GV. Metabolic syndrome, undiagnosed diabetes mellitus and insulin resistance are highly prevalent in urbanised South African blacks with coronary artery disease. Cardiovasc J S Afr. 2006;17(2):50-55.

15. Ker JA, Rheeder P, Van Tonder R. Frequency of the metabolic syndrome in screened South African corporate executives. Cardiovasc J S Afr. 2007;18(1):30-33.

16. Fezeu L, Balkau, Kengne AP, Sobngwi E, Mbanya JC. Metabolic syndrome in a sub-Saharan African setting: dentral obesity may be the key determinant. Atherosclerosis. 2007;193(1):70-76.

17. Kasiam Lasi On'kin JB, Longo-Mbenza B, Nge Okwe A, Kangola Kabangu N. Survey of abdominal obesities in an adult urban population of Kinshasa, Democratic Republic of Congo. Cardiovasc J Afr. 2007;18(5):300-307.

18. Isezuo SA, Ezunu E. Demographic and clinical correlates of metabolic syndrome in Native African type-2 diabetic patients. J Natl Med Assoc. 2005;97(4):557-563.

19. Schultz AB, Edington DW. The association between changes in metabolic syndrome and changes in cost in a workplace population. JOccup Environ Med. 2009;51(7):771-779.

20. Kawada T, Otsuka T, Inagaki H, Wakayama Y, Li Q, Katsumata M. Relationship between two indicators of coronary risk estimated by the Framingham Risk Score and the number of metabolic syndrome components in Japanese male manufacturing workers. Metab Relat Disord. 2009;7(5):335-340.

21. Schultz AB, Edington DW. Metabolic syndrome in a workplace: prevalence, co-morbidities, and economic impact. Metab Syndr Relat Disord. 2009;7(5):459-468. 
22. Kawada T, Okada K, Amezawa M. Components of the metabolic syndrome and lifestyle factors in Japanese male workers. Metab Syndr Relat Disord. 2008;6(4):263-266.

23. Yoon J, Yi K, Oh J, Lee S. The relationship between metabolic syndrome and Korean cardiocerebrovascular risk assessment: for male researchers in a workplace. [Article in Korean]. J Prev Med Public Health. 2007;40(5):397-403.

24. Oberlinner C, Humpert PM, Nawroth PP, Zober A, Marcos M. Metabolic syndrome in a large chemical company: prevalence in a screened worksite sample. Acta Diabetol. 2008;45(1):31-35.

25. No authors listed. Arterial hypertension. Report of a WHO expert committee. World Health Organ Tech Rep Ser. 1978;628:7-56.

26. Longo-Mbenza B, Nkoy Belila J, Vangu Ngoma D, Mbungu S. Prevalence and risk factors of arterial hypertension among urban Africans in workplace: the obsolete role of body mass index. Niger $J$ Med. 2007;16(1):42-49.

27. Camargo CA Jr, Hennekens CH, Gaziano JM, Glynn RJ, Manson JE, Stampfer MJ. Prospective study of moderate alcohol consumption and mortality in US male physicians. Arch Intern Med. 1007;157(1): 79-85.

28. Balkau B, Charles MA. Comment on the provisional report from the WHO consultation. European Group for the Study of Insulin Resistance (EGIR). Diabet Med. 1999;16(5):442-443.

29. Santos AC, Barros H. Impact of metabolic syndrome definitions on prevalence estimates: a study in a Portuguese community. Diabetes Vasc Dis Res. 2007;4(4):320-327.

30. Cameron AJ, Shaw JE, Zimmet PZ. The metabolic syndrome: prevalence in worldwide populations. Endocrinol Metab Clin North Am. 2004;33(2):351-375.

31. Skilton MK, Moulin P, Serusclat A, Nony P, Bonnet F. A comparison of the NCEP-ATPIII, IDF and AHA/NHLBI metabolic syndrome definitions with relation to early carotid atherosclerosis in subjects with hypercholesterolemia or at risk of CVD: evidence for sex-specific differences. Atherosclerosis. 2007;190(2):416-422.

32. Ford ES, Giles WH, Dietz WH. Prevalence of the metabolic syndrome among US adults: findings from the third National Health and Nutritional Examination Survey. JAMA. 2002;287(3):356-359.

33. Hu G, Qiao Q, Tuomilehto J, Balkau B, Borch-Johnsen K, Pyorala K; DECODE Study Group. Prevalence of the metabolic syndrome and its relation to all-cause and cardiovascular mortality in nondiabetic European men and women. Arch Intern Med. 2004;164(10): 1066-1076.
34. Sibai AM, Obeid OA, Batal M, Adra N, Dit El Khoury DT, Hwalla N. Prevalence and correlates of metabolic syndrome in an adult Lebanese population. CVD Prev Control. 2008;3(2):83-90.

35. Ozsahin AK, Gokcel A, Sezgin N, et al. Prevalence of the metabolic syndrome in a Turkish adult population. Diabetes Nutr Metab. 2004;17(4):230-234.

36. Al-Lawati JA, Mohammed AJ, Al-Hinai HQ, Jousilahti P. Prevalence of the metabolic syndrome among Omani adults. Diabetes Care. 2003;26(6):1781-1785.

37. Azizi F, Salehi P, Etemadi A, Zahedi-Asl S. Prevalence of metabolic syndrome in an urban population: Tehran Lipid and Glucose Study. Diabetes Res Clin Pract. 2003;61(1):29-37.

38. Villegas R, Xiang YB, Yang G, et al. Prevalence and determinants of metabolic syndrome according to the three definitions in middle-aged Chinese men. Metab Syndr Relat Disord. 2009;7(1):37-45.

39. Meigs JB. Invited commentary: insulin resistance syndrome? Syndrome X? Multiple metabolic syndrome? A syndrome at all? Factor analysis reveals patterns in the fabric of correlated metabolic risk factors. Am J Epidemiol. 2000;152(10):908-911.

40. Festa A, D'Agostino R Jr, Howard G, Mykkanen L, Tracy RP, Haffner SM. Chronic subclinical inflammation as part of the insulin resistance syndrome: the Insulin Resistance Atherosclerosis Study (IRAS). Circulation. 2000;102(1):42-47.

41. Lee JS, Kawakubo K, Mori K, Akabayashi A. Effective cut-off values of waist circumference to detect the clustering of cardiovascular risk factors of metabolic syndrome in Japanese men and women. Diabetes Vasc Dis Res. 2007;4(4):340-345.

42. Kawamoto R, Kohara K, Tabara Y, Miki T, Otsuka N. Serum gamma-glutamyl transferase levels are associated with wetabolic syndrome in community-dwelling individuals. J Atheroscler Thromb. 2009;16(4):355-362.

43. Esteghamati A, Jamali A, Khalilzadeh O, et al. Metabolic syndrome is linked to a mild elevation in liver aminotransferases in diabetic patients with undetectable non-alcoholic fatty liver disease by ultrasound. Diabetol Metab Syndr. 2010;2:65.

44. Kasapoglu B, Turkay C, Bayram Y, Koca C. Role of GGT in diagnosis of metabolic syndrome: a clinic-based cross-sectional survey. Indian $J$ Med Res. 2010;132:56-61.

45. Oh HJ, Kim TH, Sohn YW, et al. Association of serum alanine aminotransferase and gamma-glutamyltransferase levels within the references range with metabolic syndrome and nonalcoholic fatty liver diseases. Korean J Hepatol. 2011;17(1):27-36.
International Journal of General Medicine

\section{Publish your work in this journal}

The International Journal of General Medicine is an international, peer-reviewed open-access journal that focuses on general and internal medicine, pathogenesis, epidemiology, diagnosis, monitoring and treatment protocols. The journal is characterized by the rapid reporting of reviews, original research and clinical studies across all disease areas.

\section{Dovepress}

A key focus is the elucidation of disease processes and management protocols resulting in improved outcomes for the patient. The manuscript management system is completely online and includes a very quick and fair peer-review system. Visit http://www.dovepress.com/ testimonials.php to read real quotes from published authors. 